\title{
EDITORIAL
}

For reprint orders, please contact: reprints@futuremedicine.com

\section{Pain and its management in developing countries}

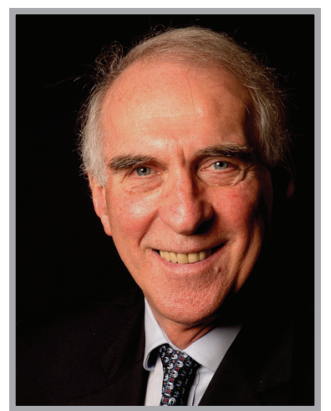

Michael Bond ${ }^{\dagger}$ "...much progress has been made in the education of those responsible for the management of pain and its treatment in the developing world. Yet, there is much to do and perhaps this brief insight will encourage readers to find ways of helping to solve the many problems that continue to exist to ensure that the right to treatment for all those in pain is fulfilled."

At the beginning of the 21st century it was very evident that despite significant advances in knowledge regarding the biological, psychological and social aspects of the experience of pain, and the development across the Western world of multiprofessional pain clinics, unimodal pain clinics, the introduction of acute pain management teams into hospitals, together with advances in pharmacological, interventionalist and psychological management, few of these advances were evident in developing countries. The International Association for the Study of Pain (IASP) decided, in 2002, to step up its aid programs for developing countries. Before that date it had provided grants for visiting lecturers and professors, IASP books for major libraries and financial support for those in developing countries who wished to attend the triennial IASP world congresses. A developing countries task group was established (the DCWG) and links with the WHO, which had existed for many years, were strengthened through grants made to $\mathrm{WHO}$ projects in developing countries.

The extent of unrelieved pain globally, but in developing countries in particular, is considerable, but reliable data regarding the prevalence and incidence of pain are limited. For example, the incidence of cancers in developing countries is increasing and severe pain afflicts $70 \%$ of late HIV/AIDS victims. Other causes of pain in developing countries include sickle cell disease, leprosy, acute pain associated with war injuries and ordinance explosions long after wars have ceased, and chronic neuropathic pain after severe limb injuries. Childbirth is a widespread cause of untreated pain in Africa and other developing countries. A WHO collaborative study of pain in primary care in developing countries revealed that chronic pain was present in approximately $5-33 \%$ of those questioned [1]. In Western countries, the figure gained from a study of European countries by Breivik and others [2], by Blyth and others in Australia [3], and Eriksen and others in Denmark [4], give figures of approximately $18 \%$. Chronic pain may be associated with depression; for example in the European Study it was present in $20 \%$ of those questioned. Significantly, the WHO study suggested that lack of adequate healthcare and social support networks, cost implications of treatment and job security were significant factors amongst those in pain but not seeking help for it. The European Study

+University of Glasgow, 2 The Square, University Avenue, Glasgow, G12 8QQ, UK

Tel.: +44 141330 2132; m.bond@admin.gla.ac.uk

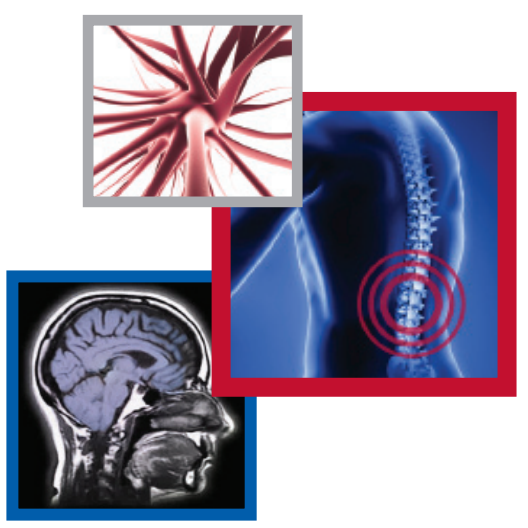

"The extent of unrelieved pain globally, but in developing countries in particular, is considerable, but reliable data regarding the prevalence and incidence of pain are limited."

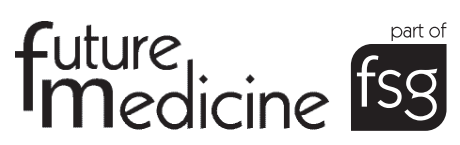


"Several fundamental problems reduce or prevent the delivery of adequate pain relief to individuals in developing countries. The results of a survey ... revealed evidence of poor pain education of health professionals, limited

facilities for pain treatment and poor access to drugs for pain relief...” revealed that $61 \%$ of individuals with chronic pain were less able, or unable, to work outside the home and that $19 \%$ lost their jobs because of pain.

Several fundamental problems reduce or prevent the delivery of adequate pain relief to individuals in developing countries. The obstacles were investigated by members of the IASP in developing countries and the results of a survey published in 2007 revealed evidence of poor pain education of health professionals, limited facilities for pain treatment and poor access to drugs for pain relief, especially in the case of strong opioids [101]. There is often a high level of opiophobia amongst government health providers, doctors, nurses and patients. The restriction of their availability to patients is demonstrated by a comparison between the countries of western and eastern Europe, which revealed that $80 \%$ of opioids are consumed in the former group: a disgraceful situation [5]! Across the world, in India it was shown in 2007 that the Government Opioid Alkaloid Works produce less than $10 \%$ of the amount of morphine needed in the country for cancer patients in pain [102], although supplies vary from state to state.

The DCWG's response to the situation that existed in the early 2000s was to first establish a system of annual, 1-year project grants, each funded to a maximum of US $\$ 10,000$. Proposals were sought from members in developing countries that reflected local needs rather than a 'top-down view' from the IASP. Since 2005, 57 grants have been distributed to 32 countries. Examples of projects include postgraduate training courses for doctors and nurses based upon the IASP core curriculum for pain education (Poland and Nigeria), courses in the use of opioid medication, including legal aspects (Romania) and a web-based distance-learning program of pain education (Brazil). The conditions for applications are rigorous and include a requirement for pre- and post-course assessments of students with the majority achieving the goals set. There is an intention, on the part of the IASP, that courses should be repeated if and when appropriate and that those who attend them should use their knowledge to help patients and also to teach others. The outcomes for courses held during the past 3 years are currently being assessed by the DCWG but it is clear already from final reports that the barriers to good pain management mentioned earlier are mirrored to some extent in them.
In addition to educational programs, the IASP has, in collaboration with the World Federation of Societies of Anesthesiology, funded clinical training programs in multidisciplinary pain clinics. The scheme began in Bangkok, where the third 1-year Fellow is in post and where three, short, 3-month clinical training courses have taken place. The 1-year Fellows, to date, have come from Malaysia, Laos and Mongolia, with 3-month training for doctors from Myanmar, Bhutan and Laos. Staff in Bangkok continue their contact with students by acting as mentors. It is intended that the Fellows will establish or enhance pain education and clinical services in their own countries.

The enthusiasm of IASP members for the programs described is very evident throughout the developing world. The programs not only provide education and training, but also stimulate IASP chapters to come together in regional groups to further the spread of basic and clinical knowledge. The first such group was pioneered by the European Federation of IASP Chapters. It incorporates western and eastern European countries into its programs. More recently, chapters in Central and South America came together, as have those in Southeast Asia.

Apart from looking 'inward' at the needs of its membership in developing countries, the IASP also provides grants for other organizations with programs in developing countries in which pain management is a major element. For example, the WHO has received support for work in Africa dealing with cancer, AIDS and palliative care, as have Kybele, an organization that aims to reduce maternal and infant mortality in developing countries, and Hospice Africa, which is involved in developing palliative care in many countries in sub-Saharan Africa.

Advocacy is a method or technique for influencing opinion. In the case of pain and its management, it is needed at government and health provider level and in the general population. This is an aim that the IASP has approached in two ways. First, since 2004 it has promoted, worldwide, six full 'IASP Global Year Against Pain' campaigns. The topics covered so far include, 'Pain Relief as a Human Right', 'Pain Relief in Children', 'Pain in Older Persons', 'Pain in Women' (all relatively neglected fields), 'Pain in Cancer', 'Musculoskeletal Pain' and 'Acute Pain'. Each IASP chapter is expected to raise the profile topic of the current year with health professionals, the general public and government. 
Other routes for advocacy are at present being explored and this process began with an inaugural 'Pain Summit' held in August this year at the IASP 13th World Congress.

The issues surrounding pain and its management in developing countries described here reveal something of the size and scope of the problems associated with the treatment of pain in those countries. A number of organizations are in their different ways and with differing objectives helping to fulfill the dictum that 'pain treatment is a human right' but there is much more to do. For example, links between charitable organizations such as the IASP, World Federation of Societies of Anesthesiology, Hospice Africa, Kybele and the government-funded WHO, which spread their activities widely across acute and chronic pain conditions, need to be extended to others working in the field of pain. There is a clamant need for all those involved in such organizations to work with patients, the general population, the media and government agencies to improve access to pain-relieving drugs and especially opiates, access to which is often very difficult and limited. It is clear that an increase in their availability and the employment of correct protocols is a matter of urgency. Improvements of this kind are possible if use is made of the guidelines published by the WHO, together with the International Narcotics Control Board on achieving balance in a national opioids control policy [103]. At the present time, the WHO is developing a program to assist countries in improving access to medications controlled under the drug conventions [6].

To conclude, much progress has been made in the education of those responsible for the management of pain and its treatment in the developing world. Yet, there is much to do and perhaps this brief insight will encourage readers to find ways of helping to solve the many problems that continue to exist to ensure that the right to treatment for all those in pain is fulfilled.

\section{Financial \& competing interests disclosure}

The author has no relevant affiliations or financial involvement with any organization or entity with a financial interest in or financial conflict with the subject matter or materials discussed in the manuscript. This includes employment, consultancies, honoraria, stock ownership or options, expert testimony, grants or patents received or pending, or royalties.

No writing assistance was utilized in the production of this manuscript.

"At the present time, the
WHO is developing a
program to assist
countries in improving
access to medications
controlled under the
drug conventions."

Eriksen J, Jensen MK, Sjøgren P, Ekholm O, Rasmussen NK: Epidemiology of chronic non-malignant pain in Denmark. Pain 106, 221-228 (2003).

5 Cherny NI, Catane R, Kosinidis PA: Problems of opioid availability and accessibility across Europe: ESMO tackles the regulatory causes of intolerable and needless suffering. Ann. Oncol. 17(6), 885-887 (2006). 287-333 (2006).

3 Blyth FM, March LM, Brnabic AJ, Jorm LR, Williamson M, Cousins MJ: Chronic pain in Australia: a prevalence study. Pain 89, 127-134 (2001).
6 Kalso E, Allan L, Dellemijn PL et al.: Recommendations for using opioids in chronic non-cancer pain. Eur. J. Pain 7, 381-386 (2003).

\section{- Websites}

101 Education and Training for Pain Management in Developing Countries; a report by the IASP Developing Countries Task Force. Published November 15th 2007. International Association for the Study of Pain, Seattle, WA, USA www-iasp.pain.org

102 Palliumindia, newsletter (23rd June 2009) http//:palliumindia.org/newsletter/

103 Achieving Balance in National Opioids Geneva, WHO (2000) http://whqlibdoc.who.int/hq/2000/ WHO_ EDM_QSM_2000.4.pdf Control Policy. Guidelines for Assessment. 